\title{
PENGARUH KONSENTRASI ZWAVELZURE AMONIAK (ZA) TERHADAP KUALITAS NATA DE COCO
}

\author{
Muhammad Rijal, Dosen Program Studi Pendidikan Biologi, \\ Fakultas Ilmu Tarbiyah dan Keguruan, IAIN Ambon, \\ 0812452891683,E-mail: rijal_rijal82@yahoo.co.id
}

\begin{abstract}
Abstrak: Hasil analisis inferensial baik indikator berat dan ketebalan diperoleh hasil pengukuran yang tertinggi adalah pada konsentrasi ZA 9 gr / $1000 \mathrm{ml}\left(\mathrm{X}_{2}\right)$ dengan nilai rata-rata tertinggi pada berat yaitu 51,6 gr dan untuk ketebalan nilai rata-rata tertinggi yaitu $1,37 \mathrm{~cm}$. Ini menunjukan bahwa kualitas nata de coco yang paling baik adalah menggunakan konsentrasi ZA 9 gr / $1000 \mathrm{ml}\left(\mathrm{X}_{2}\right)$. Data hasil penelitian dihitung dengan menggunakan uji-F,diperoleh nilai $\mathrm{F}_{\text {hitung }}=0,46$ baik untuk berat maupun ketebalannya, dan $\mathrm{F}$ tabel $5 \%=5,14$ dan $1 \%=10,92 . \mathrm{H}_{0}$ diterima karena perlakuan memberikan pengaruh tidak signifikan terhadap variabel respons.
\end{abstract}

\section{Kata Kunci: Kualitas, Nata De Coco, Za \\ THE INFLUENCE OF THE CONCENTRATION OF AMMONIA (ZA) ZWAVELZURE TO THE QUALITY OF NATA DE COCO}

\begin{abstract}
Results of the analysis of the inferensial good indicators of weight and thickness measurement results obtained the highest concentration is in the ZA $9 \mathrm{gr} / 1000$ $\mathrm{ml}\left(\mathrm{X}_{2}\right)$ with the highest average score on the weight is $51.6 \mathrm{gr}$ and to the thickness of the highest average value is $1,37 \mathrm{~cm}$. This shows that the quality of nata de coco is the best is to use concentration ZA $9 \mathrm{gr} / 1000 \mathrm{ml}\left(\mathrm{X}_{2}\right)$. Data research results calculated using the test-F, retrieved the value $\mathrm{F}=0.46$ count for both weight as well as its thickness, and $\mathrm{F}$ table $5 \%=5.14$ and $1 \%=10,92 . \mathrm{H}_{0}$ is accepted because the treatment did not significantly influence the response variable against.
\end{abstract}

\section{Keywords: Quality, Nata De Coco, Za}

Untuk di daerah Maluku,air kelapa tidak banyak di pergunakan atau diolah menjadi suatu produk, biasanya hanya dibuang begitu saja, baik di daerah-daerah pedesaan maupun di daerah-daerah perkotaan,salah satu contoh di Kota Ambon yaitu di pasar tempat 
pemarutan kelapa, yang biasanya sering kita lihat air kelapanya di buang begitu saja, sehingga lama kelamaan akan menimbulkan pencemaran lingkungan.

Mengingat potensi air kelapa yang demikian besar jumlahnya, yang setiap tahun cenderung mengalami peningkatan, maka pembuatan nata de coco yang menggunakan medium air kelapa dapat diusahakan sebagai industri rumah tangga. Selama ini masyarakat menggunakan bahan-bahan yang agak sulit diperoleh dan harganya mahal, misalnya ammonium sulfat. Padahal ammonium sulfat tersebut bisa digantikan peranannya, yaitu dengan menggunakan ZA (Zwavelzure Amoniak) yang berwarna putih dan berbentuk butiran Kristal, serta memiliki kandungan nitrogen yang sangat tinggi yang digunakan oleh Acetobacter xylinum untuk tumbuh dan memfermentasi air kelapa menjadi nata de coco.

Pupuk ZA tidak berbahaya bagi manusia, karena untuk pembuatan nata de coco, biasanya digunakan ammonium sulfat, yang pada dasarnya ammonium sulfat tersebut sama dengan pupuk ZA. Yang seperti kita ketahui dalam bahasa Belanda arti dari ZA itu sendiri adalah ammonium sulfat, hanya saja secara teknis keduanya berbeda, yaitu dari bentuk serta strukturnya, begitu pun dengan harganya, pupuk ZA relatif lebih murah dibandingkan dengan ammonium sulfat. Keduanya sama-sama memiliki kandungan nitrogen yang sangat tinggi yang sangat dibutuhkan oleh Acetobacter xylynum untuk kelangsungan metabolisme yang terjadi dan nitrogen tersebut akan di cerna/terdegradasi oleh bakteri dan tidak terkandung dalam nata karena habis di konsumsi bakteri dengan catatan kadarnya sesuai.

\section{METODE PENELITIAN}

Jenis yang digunakan dalam penelitian ini adalah korelasi dengan pendekatan eksperimen laboratorium menggunakan Rancangan Acak Lengkap (RAL) dengan 3 perlakuan dan 3 kali ulangan

Tabel 1. Desain Pengaruh Konsentrasi ZA Terhadap Berat dan Ketebalan

\begin{tabular}{|c|c|c|c|c|c|}
\hline \multirow{2}{*}{ Kualitas nata de coco } & \multicolumn{3}{|c|}{ Ulangan } & \multirow{2}{*}{ Jumlah } & \multirow{2}{*}{ Rerata } \\
\cline { 2 - 4 } & $\mathbf{1}$ & $\mathbf{2}$ & $\mathbf{3}$ & & \\
\hline Konsentrasiza & $\mathrm{X}_{1} \mathrm{Y}_{1}$ & $\mathrm{X}_{1} \mathrm{Y}_{2}$ & $\mathrm{X}_{1} \mathrm{Y}_{3}$ & $\mathrm{~T}_{1}$ & \\
\hline Konsentrasi 3 gr/4000 $\mathrm{ml}\left(\mathrm{X}_{1}\right)$ & $\mathrm{X}_{2} \mathrm{Y}_{1}$ & $\mathrm{X}_{2} \mathrm{Y}_{2}$ & $\mathrm{X}_{2} \mathrm{Y}_{3}$ & $\mathrm{~T}_{2}$ & \\
\hline Konsentrasi $\left.15 \mathrm{gr} / 1000 \mathrm{ml} / \mathrm{X}_{2}\right)$ & $\mathrm{X}_{3} \mathrm{Y}_{1}$ & $\mathrm{X}_{3} \mathrm{Y}_{2}$ & $\mathrm{X}_{3} \mathrm{Y}_{3}$ & $\mathrm{~T}_{3}$ & \\
\hline
\end{tabular}

Keterangan:

$\mathrm{X}=$ Konsentrasi ZA

$\mathrm{Y}=$ Berat dan Ketebalan nata de coco 


\section{Variable Penelitian}

1. Variable bebas (X) adalah konsentrasi ZA, terdiri dari $\mathrm{X}_{1}$ (Konsentrasi $3 \mathrm{gr} / 1000 \mathrm{ml}$ ), $\mathrm{X}_{2}$ ( Konsentrasi $9 \mathrm{gr} / 1000 \mathrm{ml}$ ), $\mathrm{X}_{3}$ (Konsentrasi $15 \mathrm{gr} / 1000 \mathrm{ml}$ )

2. Variable terikat (Y) adalah kualitas nata de coco, yaitu rendemen ( berat ) dan ketebalan.

Penelitian ini telah dilaksanakan dan berlangsung selama 2 minggu mulai dari tanggal 7 Agustus sampai 21 Agustus 2012. Penelitian ini bertempat di Laboratorium MIPA Institut Agama Islam Negeri (IAIN) Ambon Jln. H. Tarmizi Taher Kode Pos 97128. Obyek dalam penelitian ini adalah pengaruh konsentrasi ZA terhadap kualitas nata de coco. Dalam penelitian ini digunakan 3 perlakuan dan 3 kali ulangan sebagai total unit pengamatan 9 unit. 1 kali ulangan menggunakan air kelapa sebanyak 1000 ml, jadi total air kelapa yang digunakan adalah $3000 \mathrm{ml}$.

\section{Prosedur Penelitian}

Ke dalam $1000 \mathrm{ml}$ air kelapa dilarutkan 10 gr gula pasir, dan ZA sesuai dengan konsentrasi yang diinginkan, selama 10 menit. Tambahkan asam asetat glasial 1,25 ml dan dibiarkan mendidih selama 10 menit. Biarkan medium dingin dalam keadaan panci tertutup. Setelah dingin medium dituang pada botol kultur dan diberi inokulum Acetobacter xylinum sebanyak $2 \mathrm{ml}$, tutup botol kultur dengan aluminium foil dan biarkan selama 2 minggu. Untuk konsentrasi ZA yang lainnya, prosedurnya sama, hanya jumlah ZA yang digunakan berbeda.

Setelah waktu fermentasi berlangsung selama 14 hari, maka nata de coco siap dipanen. Untuk pengukuran berat nata de coco dilakukan dengan timbangan Ohaus 8724 dengan kapasitas 311 gr. Disamping itu diadakan pool pendapat dari 10 responden mengenai warna (tingkat keputihan), dan tingkat kekenyalan. Jumlah responden sebanyak 10 orang dengan kriteria adalah orang yang sering mengkonsumsi nata de coco. Untuk pengukuran ketebalan nata de coco digunakan mistar.

Pengumpulan data dilakukan dengan menimbang berat nata de coco yang dihasilkan. Kemudian dilakukan uji organoleptik oleh responden dari hasil nata de coco. Untuk ketebalan diperoleh melalui metode pengukuran dengan satuan $\%$.

1. Analisis Deskriptif, dilakukan untuk membahas kualitas (uji organoleptik) dari Warna, dan kekenyalan nata de coco dengan menggunakan angket (lembar isian responden)

2. Analisis inferensial dilakukan untuk menguji hipotesis terkait rendemen dan ketebalan dengan model:

$$
\mathrm{Y}_{\mathrm{ij}}=\mu+\tau_{\mathrm{j}}+\varepsilon_{\mathrm{ij}}
$$




\section{HASIL DAN PEMBAHASAN}

1. Warna (tingkat keputihan) Nata de Coco

Dari hasil uji organoleptik terhadap warna (tingkat keputihan) nata de coco dari tiga konsentrasi ZA yang berbeda yakni 3 gr / 1000 ml, 9 gr / 1000 ml dan 15 gr / 1000 $\mathrm{ml}$, sesuai dengan pendapat dari 10 orang responden yang diambil dari mahasiswa yang sering mengkonsumsi nata de coco yaitu 6 orang responden menilai warnanya putih, 2 orang responden menilainya cukup putih dan 2 orang responden menilai warnanya kurang putih.

2. Kekenyalan Nata de Coco

Dari hasil uji organoleptik terhadap tingkat kekenyalan nata de coco dari tiga konsentrasi ZA yang berbeda sesuai dengan pendapat dari 10 orang responden yang di ambil dari mahasiswa yang sama dalam menilai warna (tingkat keputihan) nata de coco yakni 9 orang responden menilainya cukup kenyal dan 1 orang responden menilainya kurang kenyal.

3. Berat Nata de Coco

Dari hasil pengukuran berat nata de coco dari tiga konsentrasi ZA yakni konsentrasi $3 \mathrm{gr} / 1000 \mathrm{ml}\left(\mathrm{X}_{1}\right), 9 \mathrm{gr} / 1000 \mathrm{ml}\left(\mathrm{X}_{2}\right)$ dan $15 \mathrm{gr} / 1000 \mathrm{ml}\left(\mathrm{X}_{3}\right)$ disajikan dalam table 11 pada lampiran 1 , sedangkan nilai rata-rata hasil pengukuran terhadap berat dari tiga konsentrasi tersebut disajikan dalam tabel di bawah ini

Tabel 2. Rata-Rata Berat Nata de Coco yang Dihasilkan dari Ketiga Konsentrasi

\begin{tabular}{|c|l|c|}
\hline No & \multicolumn{1}{|c|}{ Perlakuan } & Rata-rata Berat Nata de Coco \\
\hline 1. & Konsentrasi $3 \mathrm{gr} / 1000 \mathrm{ml}$ & $48,7 \mathrm{gr}$ \\
\hline 2. & Konsentrasi $9 \mathrm{gr} / 1000 \mathrm{ml}$ & $51,6 \mathrm{gr}$ \\
\hline 3. & Konsentrasi $15 \mathrm{gr} / 1000 \mathrm{ml}$ & $37,7 \mathrm{gr}$ \\
\hline
\end{tabular}

Berdasarkan dari hasil pengukuran terhadap nilai rata-rata berat nata de coco pada table diatas, terlihat bahwa hasil pengukuran berat nata de coco yang tertinggi diperoleh pada perlakuan konsentrasi 9 gr / $1000 \mathrm{ml}\left(\mathrm{X}_{2}\right)$, dengan nilai rata-rata 51,6 gr. Setelah dilakukan perhitungan Uji-F untuk berat nata de coco dari ketiga perlakuan konsentrasi ZA yang berbeda, diperoleh nilai $F$ hitung $(0,46)<F_{\text {tabel }}$, oleh karena itu, maka $\mathrm{H}_{\mathrm{O}}$ diterima yang berarti tidak ada perbedaan pengaruh konsentrasi ZA terhadap berat nata de coco yang dihasilkan.

4. Ketebalan Nata de Coco

Dari hasi pengukuran ketebalan nata de coco dari ketiga konsentrasi ZA yakni konsentrasi $3 \mathrm{gr} / 1000 \mathrm{ml}\left(\mathrm{X}_{1}\right), 9 \mathrm{gr} / 1000 \mathrm{ml}\left(\mathrm{X}_{2}\right)$ dan $15 \mathrm{gr} / 1000 \mathrm{ml}\left(\mathrm{X}_{3}\right)$ disajikan dalam table 12 pada lampiran 1 , sedangkan nilai rata-rata hasil pengukuran terhadap ketebalan dari ketiga konsentrasi tersebut disajikan dalam tabel di bawah ini 
Tabel 3. Rata-rata ketebalan nata de coco yang dihasilkan dari ketiga konsentrasi

\begin{tabular}{|c|l|c|}
\hline No & \multicolumn{1}{|c|}{ Perlakuan } & Rata-rata ketebalan nata de coco \\
\hline 1. & Konsentrasi $3 \mathrm{gr} / 1000 \mathrm{ml}$ & $1,30 \mathrm{~cm}$ \\
\hline 2. & Konsentrasi $9 \mathrm{gr} / 1000 \mathrm{ml}$ & $1,37 \mathrm{~cm}$ \\
\hline 3. & Konsentrasi $15 \mathrm{gr} / 1000 \mathrm{ml}$ & $0,97 \mathrm{~cm}$ \\
\hline
\end{tabular}

Berdasarkan dari hasi pengukuran terhadap nilai rata-rata ketebalan nata de coco pada table di atas, terlihat bahwa hasil pengukuran ketebalan nata de coco yang tertinggi diperoleh pada perlakuan konsentrasi $9 \mathrm{gr} / 1000 \mathrm{ml}\left(\mathrm{X}_{2}\right)$ dengan nilai rata-rata 1,37 cm. Sedangkan analisis sumber ragam terhadap nilai rata-rata ketebalan nata de coco pada ketiga konsentrasi ZA tersebut dapat dilihat pada tabel di bawah ini, dan perhitungan disajikan dalam analisis Uji-F. Setelah dilakukan perhitungan Uji-F untuk ketebalan nata de coco dari ketiga perlakuan konsentrasi ZA yang berbeda, diperoleh nilai $F_{\text {hitung }}(0,46)$ $<\mathrm{F}$ tabel, oleh karena itu, maka $\mathrm{H}_{\mathrm{O}}$ diterima yang berarti tidak ada perbedaan pengaruh konsentrasi ZA terhadap ketebalan nata de coco yang dihasilkan.

Pupuk ZA mengandung Nitrogen (20-21\%), sulfur (23-24\%). Karena banyaknya kandungan sulfurnya maka pupuk ZA sangat berguna bagi pertumbuhan tanaman yang banyak membutuhkan unsur belerang. Dalam pembuatan nata de coco memerlukan bantuan mikroorganisme, dalam hal ini adalah bakteri aerob yaitu Acetobacter xylinum dan bakteri tersebut mempunyai berbagai kriteria kehidupan seperti kadar keasaman $(\mathrm{pH})$ 3-4 dan ketersediaan nitrogen yang cukup, sehingga ZA yang ada merupakan sumber nitogen bagi kelangsungan proses metabolisme yang terjadi dan nitrogen tersebut akan di cerna / terdegradasi oleh bakteri dan tidak terkandung dalam nata karena habis di konsumsi bakteri dengan catatan kadarnya sesuai.

Hasil analisis deskriptif kualitatif pada uji organoleptik mengenai warna dan kekenyalan nata de coco dari ketiga konsentrasi yang berbeda yakni 3 gr / $1000 \mathrm{ml}\left(\mathrm{X}_{1}\right)$, $9 \mathrm{gr} / 1000 \mathrm{ml}\left(\mathrm{X}_{2}\right)$ dan $15 \mathrm{gr} / 1000 \mathrm{ml}\left(\mathrm{X}_{3}\right)$, memperlihatkan adanya perbedaan yang dibuktikan dari pendapat ke 10 orang responden, yang hasilnya menunjukan tidak semua dari ketiga konsentrasi ZA tersebut sama, dalam hal ini ada yang menilai warnanya ( tingkat keputihan ) putih, cukup putih, dan kurang putih serta untuk tingkat kekenyalan ada yang menilainya cukup kenyal dan kurang kenyal.

Untuk hasil analisis deskriptif kuantitatif pada berat dan ketebalan nata de coco, dimana nilai rata-rata pada konsentrasi 3 gr / $1000 \mathrm{ml}\left(\mathrm{X}_{1}\right)$ untuk berat 48,7 gr, ketebalannya $1,30 \mathrm{~cm}$, konsentrasi $9 \mathrm{gr} / 1000 \mathrm{ml}\left(\mathrm{X}_{2}\right)$ untuk berat 51,6 gr, ketebalannya $1,37 \mathrm{~cm}$, dan konsentrasi $15 \mathrm{gr} / 1000 \mathrm{ml}\left(\mathrm{X}_{3}\right)$ untuk berat 37,7 gr, ketebalannya $0,97 \mathrm{~cm}$ , ini menunjukan bahwa adanya perbedaan nilai rata-rata dari berat dan ketebalannya , 
dimana untuk berat dan ketebalan nata de coco yang lebih besar mengacu pada konsentrasi 9 gr / $1000 \mathrm{ml}\left(\mathrm{X}_{2}\right)$. Penelitian ini membuktikan bahwa dari ketiga konsentrasi ZA yang digunakan sebagai tambahan nutrisi yang digunakan oleh bakteri nata yaitu Acetobacter xylinum, ternyata konsentrasi ZA 9 gr / $1000 \mathrm{ml}\left(\mathrm{X}_{2}\right)$ memberikan produk nata de coco yang terbaik, baik dari segi warna, kekenyalan maupun dari segi berat dan ketebalannya.

\section{KESIMPULAN}

1. Ada perbedaan pengaruh konsentrasi ZA terhadap warna dan kekenyalan produk nata de coco, tetapi tidak ada perbedaan pengaruh konsentrasi terhadap berat dan ketebalan produk nata de coco.

2. Konsentrasi ZA yang terbaik dalam penelitian ini adalah $9 \mathrm{gr} / 1000 \mathrm{ml}$.

\section{SARAN}

1. Disarankan kepada pembuat nata de coco untuk memberikan ZA pada konsentrasi 9 gr / $1000 \mathrm{ml}$ dalam medium yang digunakan.

2. Pengaruh pemberian konsentrasi ZA yang lebih tinggi atau lebih rendah dalam proses fermentasi air kelapa terhadap kualitas nata de coco tidak akan menghasilkan produk nata de coco yang berkualitas, sehingga diperlukan konsentrasi yang optimum untuk pertumbuhan nata de coco yang baik dan optimal.

3. Perlunya diperhatikan alat, bahan, dan ruangan tempat fermentasi nata de coco yang benar-benar steril ( bebas dari kontaminan ).

\section{DAFTAR PUSTAKA}

Anonim. 1998. Dasar-Dasar Bercocok Tanam. Kanisius. Yokyakarta Indranada H.K. 1989. Pengelolaan Kesuburan Tanah. Bina Aksara. Jakarta Hanafiah A.K. 1993. Rancangan Percobaan. Raja Grafindo. Jakarta Indranada H.K. 1989. Pengelolaan Kesuburan Tanah. Bina Aksara. Jakarta Joseph G.H. 2008. Tingkat Keasaman Medium Terhadap Fermentasi Nata De Coco. Balai Penelitian Kelapa; Manado

La Teng N.P. 1990. Pengaruh Pupuk dan Jumlah Sel Mikroba Starter pada Pembuatan Nata De Coco.UNHAS. Ujung Pandang

Noverta EBT. 1996. Budidaya kelapa Kopyor. Mataram Agung. Jakarta Palunkun R. 1993. Aneka Produk Olahan Kelapa. Penebar Swadaya. Jakarta Pambayun R. 2002. Teknologi Pengolahan Nata De Coco. Kanisius. Yokyakarta Setyamidjaja D. 1991. Bertanam Kelapa. Kanisius. Yokyakarta 
Sofyan A. 1994. Studi Beberapa Pupuk Nitrogen dengan Rhizobium Terhadap Hasil Panen Kacang-Kacangan. Balai Pengkajian Teknologi Pertanian. Malang

Suhardiyono. 1993. Tanaman Kelapa dan Pemanfaatannya. Kanisius. Yokyakarta Sumartono. 1982. Kelapa. Bumi Restu. Jakarta

Sutrisno T. 1989. Pemupukan dan Pengolahan Tanah. Armico. Bandung

Setyaji Yunanto. 2011. Pengaruh Pemberian Nata De Coco terhadap Kadar Kolesterol LDL dan HDL pada Tikus Hiperkolesterolemia. Artikel Penelitian . Program Studi Ilmu Gizi Fakultas Kedokteran. Universitas Diponegoro

Warisno. 1998. Budidaya Kelapa Kopyor.Kanisius. Yokyakarta

Warisno. 1998. Mudah dan Praktis Membuat Nata De Coco. Agro Media. Yokyakarta 